\title{
Childhood Meningeal Melanoma
}

National Cancer Institute

\section{Source}

National Cancer Institute. Childhood Meningeal Melanoma. NCI Thesaurus. Code C5318.

A melanoma that arises from leptomeningeal melanocytes and occurs in childhood. 